\title{
NEGOCIAÇÕES MULTILATERAIS DO COMÉRCIO DE SERVIÇOS, INTERVENÇÃO ESTATAL BRASILEIRA E DEFESA DOS INTERESSES NACIONAIS
}

\author{
Fátima Faro ${ }^{1}$ \\ Ricardo Faro ${ }^{2}$
}

\section{Resumo}

O artigo Negociações multilaterais do comércio de serviços, intervenção estatal brasileira e defesa dos interesses nacionais comenta a trajetória e evolução das negociações multilaterais envolvendo o comércio de serviços, e o seu reflexo na formatação do modelo implementado pelo Brasil para fomento dessa atividade econômica, e defesa de nossos interesses estratégicos e prioritários nos fóruns internacionais.

Palavras-chave: Desenvolvimento; Comércio de Serviços; Negociações multilaterais; Países Emergentes;

\begin{abstract}
The purpose of this article is to discuss the evolution of the multilateral negotiations focused on trade of services, as well as the Brazilian governmental politics to emphasize the development of this economic activity, and to support our participation within the bilateral and multilateral rounds of negotiation, from an individual country perspective, according to the national point of view.
\end{abstract}

Key-words: Development. Trade of Services. Multilateral Negotiations. Emerging Countries.

\section{Considerações Iniciais}

O interesse mundial pela intervenção nos rumos do comércio de serviços tem crescido de maneira representativa, sobretudo a partir da segunda metade dos anos 90, logo após a conclusão da Rodada Uruguai de Negociações Multilaterais.

Essa atividade econômica tem observado uma elevação substancial em sua respectiva cota de participação nas economias, representando, hoje, cerca de $80 \%$ do Produto Interno Bruto dos chamados países desenvolvidos.

Esse fato, embora replicado em menor escala junto aos estados soberanos detentores de um nível de desenvolvimento significativamente mais baixo, a exemplo do Brasil, de qualquer maneira já alcança, em média, $60 \%$ do PIB dessas nações, demonstrando a sua força na composição das transações econômicas internacionais.

\footnotetext{
1 Doutoranda em Economia pela UNB - Brasília - DF, Mestre em Economia pela Escola de Pós-Graduação em Economia da Fundação Getúlio Vargas do Rio de Janeiro, Bacharel em Ciências Econômicas pela AEUDF Brasília - DF, Consultora de empresas públicas e privadas em projetos regional-urbano-turístico, Membro da Comissão de Especialistas do MEC e Professora do UniCeub.

2 Especialista em Comércio Exterior com pós-graduação Lato Sensu pelo ICAT/AEUDF - Brasília - DF, Bacharel em Administração pela AEUDF - Brasília - DF, Analista Sênior da Diretoria de Comércio Exterior do Banco do Brasil S.A., e Professor Universitário.
} 
Isto não se deu por acaso. A demanda crescente por esse segmento deriva do progresso e desenvolvimento dos estudos científicos que possibilitaram ao homem não apenas ampliar o espectro de abrangência, mas sobretudo diversificar a atividade econômica e suas formas de exploração, gerando necessidades anteriormente não previstas ou mesmo nunca sentidas até então.

Os avanços registraram um ritmo crescente e significativo, principalmente, em virtude do advento e evolução da tecnologia de informação e da comunicação - TIC, dinamizando o oferecimento de soluções para apoiar desde as mais singelas tarefas, até a gestão de sofisticados e complexos processos pelos quais somos responsáveis, qualquer que seja a sua respectiva área de atuação e influência.

Os serviços são extremamente relevantes para a economia porque além de se comportar como um negócio em si, operam como um elemento chave na composição da base de apoio e de sustentação das atividades empreendidas pelos setores produtivos, destacando-se, nesse caso, a logística e os transportes, e ainda, o suporte jurídico, contábil, financeiro e gerencial.

Em face disso, é legítimo acreditar que a partir dos movimentos em prol da expansão do nível de trocas econômicas, decorrentes da aproximação gradativa das nações, e conjugados com a preocupação contínua do mundo moderno em estabelecer parâmetros para o balizamento das relações internacionais, a ocupação pelo tema, de um espaço privilegiado nas agendas dos países que se constituem nos maiores players do comércio, uma conseqüência natural dessas iniciativas.

\section{As Negociações Multilaterais Acerca do Comércio de Serviços}

Há relatos de que apenas no decorrer da década de 70 o termo "comércio de serviços" teria surgido nas discussões internacionais relacionadas à performance dessa atividade econômica, substituindo a expressão "transações com invisíveis", fruto de uma ação específica da Organização para Cooperação e Desenvolvimento Econômico - OCDE, que se preocupou em desenvolver um estudo voltado para a efetivação de análises estruturais a respeito da sua trajetória e impacto nas contas nacionais dos países membros daquela associação.

Esses debates, inicialmente, revelaram-se por demais tímidos, vindo a se tornar mais efetivos e influentes apenas na década seguinte, principalmente devido a uma relativa perda de competitividade norte-americana no cenário internacional, fruto, em primeiro plano, de uma severa tensão nos negócios do setor petrolífero.

Posteriormente, esse cenário negativo foi intensificado pelo comprometimento da saúde financeira do sistema bancário, e pela consolidação do poder de outros blocos econômicos, dos quais os EUA não eram partes integrantes. 
Até então, não se vislumbrava, ou pelo menos não se aspirava discutir fortemente o tema em paralelo às negociações relacionadas ao comércio de bens. Houve, inclusive, uma tentativa de simplesmente se debater a matéria no contexto do GATT (General Agreement on Tariffs and Trade), sem envolver a formatação de um acordo em separado.

A iniciativa foi rechaçada de forma peremptória pelos países emergentes, face à percepção de que as assimetrias e pontos de vista desconexos, já existentes entre as nações desenvolvidas e em desenvolvimento, quanto ao comércio de bens, seriam replicados em relação ao comércio de serviços.

Esses atores suspeitavam de que o acesso aos mercados de seus respectivos interesses, relativamente aos produtos em que se mostrassem competitivos, fosse lançado, com algumas reservas, como moeda de troca para um processo rápido e expressivo de liberalização do intercâmbio de serviços, contribuindo para ampliar o grau de insatisfação entre os players envolvidos, e com isso, restringindo as possibilidades de um entendimento que produzisse efeitos positivos para todos os intervenientes.

Pode-se afirmar, no entanto, que esse posicionamento externado pelas nações emergentes foi imperativo para o advento do GATS (General Agreement on Trade in Services) acordo que na prática, representa apenas um ponto de partida para um entendimento multilateral, a partir do qual as nações organizadas pudessem disciplinar o comércio de serviços em quase todas as variações, exceto no que diz respeito a certos segmentos, a exemplo dos serviços prestados em razão do exercício da autoridade governamental, além dos direitos de tráfego aéreo e atividades direta ou indiretamente relacionadas.

De qualquer maneira, há muito que se evoluir nesse sentido, até porque o processo de negociação está longe de se mostrar conclusivo, pelo menos o suficiente de forma a suavizar a pressão nas agendas internacionais dos países negociadores.

\section{As Barreiras ao Comércio de Serviços}

Diferentemente do comércio de bens, as principais barreiras responsáveis por reduzir a capacidade de o comércio de serviços vir a se desenvolver plenamente não dizem respeito à cobrança de direitos aduaneiros (barreiras tarifárias). Os obstáculos hoje observados concentram-se, basicamente, no desconhecimento parcial e, por vezes, até mesmo total, acerca do universo de transações, características e demais particularidades desse mercado, dependendo do país e sub-setor sob análise.

Além disso, também concorre para agravar esse quadro uma aparente falta de transparência dos instrumentos normativos e demais dispositivos regulamentares que orientam a execução de serviços, combinada com as restrições vigentes, quanto à sua outorga aos prestadores de origem estrangeira, em condições favoráveis ou equivalentes aos prestadores domésticos. 
No comércio de serviços, a identificação das barreiras e o correto equacionamento dos casos concretos ganham uma grande dimensão face à dificuldade em acionar os mecanismos possíveis de serem utilizados num esforço para superar os obstáculos detectados.

Essas dificuldades decorrem do complexo nível de desagregação possível para cada setor e sub-setor, de acordo com os quatro modos de prestação de serviços definidos por aquele acordo internacional, ${ }^{3}$ mas sobretudo em virtude da prerrogativa de os países signatários do GATS incluírem ou não, numa lista positiva, os segmentos elegíveis para debate, delimitando-se, portanto, o que pode e o que não pode ser discutido numa rodada de negociação.

\section{A Estratégia Brasileira para Superação das Barreiras ao Comércio de Serviços}

As deficiências dos instrumentos de mensuração, o acompanhamento e a gestão do segmento, em vigor no Brasil, contribuem para obstar o tratamento adequado do tema.

Face à não existência de dados estatísticos fidedignos acerca da nossa performance no mercado de serviços, temos enfrentado uma situação de real dificuldade em reconhecer quais os setores em que, de fato, somos efetivamente competitivos, ou mesmo apontar aqueles que necessitam de um estímulo considerável, de maneira a possibilitar o desenvolvimento de vantagens comparativas, o que poderá contribuir, sobremaneira, para a alavancagem dos negócios de interesse nacional.

Na opinião de alguns especialistas, com larga experiência no exame dessas questões, o grande problema do Brasil reside no fato de que a metodologia aplicada por nossas autoridades monetárias para a geração de informações privilegiadas, baseia-se no modelo de "Balanço de Pagamentos" defendido pelo Fundo Monetário Internacional.

A captação e a análise dos dados obtidos junto ao Balanço de Pagamentos, configurado dessa forma, pode ensejar a observação de algumas distorções em seu resultados, interferindo, talvez, de forma negativa, na execução de políticas destinadas a corrigir as deficiências do segmento e orientá-lo de forma satisfatória. ${ }^{4}$

O Governo Federal, todavia, não aparenta desconhecer que é extremamente necessário o quanto antes implementar um sistema de apuração e controle de dados estatísticos aperfeiçoados, tornando possível a obtenção de informações gerenciais confiáveis, que possam subsidiar a execução de políticas passíveis de aplicação ao segmento, vindo, dessa

\footnotetext{
${ }^{3}$ Modo 1 - serviços transfronteiriços; Modo 2 - consumo no exterior; Modo 3 - presença comercial; e Modo 4 movimentação temporária de pessoas físicas.

4 As transações registradas no Balanço de Pagamentos dizem respeito às movimentações realizadas entre residentes e não residentes. Para esse efeito, o BP enxerga a residência sob contexto da jurisdição da localização geográfica de uma determinada área de interesse, desconsiderando a nacionalidade dos agentes. Em função da dificuldade em qualificar alguns segmentos do mercado serviços quanto ao local exato de sua área de interesse, foi sugerido pelo FMI a aplicação do princípio da temporalidade, ou seja, o enquadramento de um determinado setor ou sub-setor ou atividade vinculada, se daria em função do seu respectivo tempo de execução num local previamente determinado.
} 
forma, a satisfazer as nossas necessidades, e municiar os nossos negociadores com argumentos sólidos para a defesa dos interesses brasileiros nos fóruns internacionais.

A estratégia empreendida por nossas autoridades para promover a inserção competitiva de nossos negócios no cenário internacional está consubstanciada em dois movimentos, um voltado para a modelagem de suporte às negociações externas e outro estrutural, voltado para a gestão interna do mercado serviços, e edificação de uma plataforma destinada a suportar os negócios do setor.

Embora não tenham sido iniciadas ao mesmo tempo, e ainda que envolvam dinâmicas e passos diferenciados, na prática, tais iniciativas acabam por apresentar uma forte conexão entre si, em virtude dos seus respectivos propósitos e pontos de convergência.

O primeiro movimento foi implementado a partir da construção de uma metodologia de abordagem e tratamento da matéria, como subsídio a formulação das propostas e, em última análise, do posicionamento brasileiro nos fóruns internacionais de negociação.

Com esse fito, foi instituído o GICI (Grupo de Trabalho sobre Comércio Internacional de Mercadorias e de Serviços), coordenado pelo Ministério das Relações Exteriores - MRE, e integrado pelos demais órgãos e entidades governamentais com ingerência no segmento, além de representantes dos setores produtivos com expressiva participação na economia, de forma a orientar a atuação brasileira na defesa dos nossos interesses.

O GICI é responsável pela discussão interna dos temas relevantes para o desenvolvimento do comércio de serviços, com base nas aspirações de cada segmento, suas fragilidades e respectivos pontos fortes, e considerando, ainda, a tendência das negociações, os espaços e margens para manobras eventualmente existentes, e sobretudo, as diretrizes já formuladas por nossas autoridades sob a ótica estratégica, tática e econômica. ${ }^{5}$

Tais iniciativas pressupõem, respectivamente, a implementação das seguintes ações, coordenadas entre si:

1. Apoio à tese que considera o multilateralismo como o canal adequado para os países emergentes defenderem a adoção de parâmetros e regras internacionais mais equilibradas, de maneira a reduzir o poder e a pressão dos países desenvolvidos no comércio de serviços;

2. Busca pela promoção de avanços sistemáticos e contínuos em todas as esferas de negociação;

\footnotetext{
${ }^{5}$ A formulação das propostas brasileira relativamente ao comércio internacional de bens e serviços não se restringe ao GICI. Também cabe ao MRE a coordenação da SENALCA (Seção Nacional de Coordenação dos Assuntos relativos à ALCA), SENEUROPA (Seção Nacional de Coordenação dos Assuntos relativos à Associação Inter-Regional Mercosul-União Européia). Dependendo dos atores envolvidos e instâncias negociadoras, é natural e até mesmo óbvio que a proposta brasileira conformada no GICI apresente, em princípio, basicamente, a mesma configuração daquela elaborada no âmbito da SENALCA e da SENEUROPA.
} 
3. Identificação clara e concisa dos temas prioritários para discussão em cada fórum de debate.

O segundo movimento governamental, implementado no sentido de induzir o mercado de serviços a aflorar todas as suas potencialidades, oferecendo as condições adequadas para o seu respectivo desenvolvimento, envolveu a criação, no âmbito do Ministério do Desenvolvimento, Indústria e Comércio Exterior - MDIC, da Secretaria de Comércio e Serviços - SCS.

A SCS é responsável pela elaboração e a execução de políticas aplicáveis ao comércio de serviços, com foco na implementação de sistemas confiáveis de coleta, tratamento e divulgação de informações sobre o comércio de serviços.

Entre outras atribuições, aquela Secretaria também ocupa-se das iniciativas voltadas para favorecer o crescimento do mercado de serviços, consubstanciadas na sua respectiva desregulamentação, desburocratização dos mecanismos de controle, adoção de medidas corretivas com vistas a reduzir os custos que interferem na formação do preço final dos serviços, combate à informalidade, e, logicamente, apoio às demais esferas de poder e de competência nas negociações internacionais.

No compasso da implementação dessa estrutura organizacional voltada para a gestão dessa atividade, foi anunciado recentemente pelo Governo Federal a criação da "Câmara de Exportação de Serviços", um órgão consultivo sob a coordenação conjunta da Secretaria de Comércio Exterior do MDIC e a Associação de Comércio Exterior do Brasil - AEB, com foco particular em cinco eixos temáticos de discussão e análise: I) financiamento e crédito; II) desburocratização; III) serviços de transporte e logística; IV) negociações internacionais; e, V) aferição e tratamento de dados estatísticos.

\section{Críticas ao Modelo Brasileiro de Gestão do Comércio de Serviços}

Não obstante a preocupação brasileira em debater de forma organizada e sistêmica o comércio de serviços em todas as suas nuances, envolvendo os segmentos chaves da sociedade civil para o correto equacionamento do assunto, as críticas internas acerca da nossa atuação internacional na defesa dos nossos interesses, por vezes, são bastante contundentes.

Alguns articulistas alegam que o Brasil não tem tido fôlego o suficiente para resistir à pressão dos países mais desenvolvidos, e que, em face disso, os nossos avanços em termos de acesso aos mercados estrangeiros são pífios, e a obtenção de condições gerais favoráveis, relativamente aos setores econômicos onde de fato somos competitivos, têm colecionado muito mais revezes do que sucessos.

Argumenta-se, inclusive, que a política externa empreendida como um todo por nossas autoridades afigura-se de certa forma equivocada, sobretudo porque, em alguns grandes "lances" do tabuleiro das negociações internacionais, principalmente no que diz respeito à 
aproximação bilateral com certas nações, busca-se, de forma precipitada, a obtenção de resultados imediatos, que nem sempre, na opinião desses observadores, traduzem-se em acertos.

Em alguns casos, procura-se enfatizar que esses supostos insucessos estariam decorrendo não devido a uma falta de habilidade dos nossos negociadores, mas em virtude da orientação governamental emanada da corrente ideológica vigente, a exemplo do processo de reconhecimento da China como uma economia de mercado, em troca de um eventual posicionamento favorável daquele País à candidatura brasileira a um assento permanente no Conselho de Segurança da Organização das Nações Unidas - ONU, na hipótese da ampliação daquele colegiado.

No caso da China, em particular, de fato existem muitos indicadores que poderiam ser apontados como base de sustentação para negar àquele País o status de economia de mercado, fundamentalmente em decorrência do nível de intervenção estatal observado junto aos setores produtivos domésticos, o que, em princípio, desqualificaria o esforço de nossas autoridades em assim justificar a decisão tomada nesse sentido.

Por outro lado, aquele País figura como um dos maiores atores em ascensão no comércio mundial, não sendo recomendável, portanto, ignorar a sua força e o seu poder de fogo.

É preciso lembrar, acima de tudo, que a China, além da Rússia, Índia, e do próprio Brasil, formam um bloco denominado "BRICS", países acerca dos quais, acredita-se que em aproximadamente 40 anos, suas respectivas economias juntas serão maiores que as economias do chamado grupo G-6, integrado pelos EUA, Japão, Alemanha, França, Itália e Reino Unido.

Portanto, independentemente de outros interesses estratégicos que porventura tenhamos, em face do gigantismo do potencial de consumo e da capacidade de geração de negócios da China, é interessante que se trabalhe proficuamente para construir oportunidades, iniciativa que por sua vez, poderia ser apontada como um argumento válido para justificar a postura brasileira.

Apenas como ilustração, um estudo publicado em 2005 pelo Instituto de Pesquisa Econômica Aplicada - IPEA revela que a conseqüência imediata da validação do status de economia de mercado para a China envolve apenas a alteração do "preço de mercado" a ser considerado para efeito das investigações realizadas pela Defesa Comercial Brasileira, podendo até dificultar a comprovação de eventual situação de dumping, mas de forma nenhuma impedindo a sua constatação. ${ }^{6}$

\footnotetext{
${ }^{6}$ Segundo esse estudo, mesmo nas situações mais críticas, ou seja, não sendo possível concluir pela legitimidade da aplicação das medidas anti-dumping, ainda que tal investida seja real, e ocorra de forma velada, as importações brasileiras oriundas da China atingiriam, aproximadamente, o patamar de US\$ 30 milhões, montante irrelevante para, isoladamente, provocar a geração de prejuízos graves, ou ameaças de prejuízos graves à indústria nacional num primeiro momento. Esse fato, no entanto, não exonera a possibilidade de no futuro essa situação vir a sofrer uma alteração conjuntural nesse sentido. Dessa forma, cabe ao governo federal monitorar o
} 
As críticas acerca da postura brasileira na condução das políticas aplicáveis ao mercado serviços não se restringem à modelagem utilizada para suportar a nossa participação nos fóruns internacionais, como também, ao nosso perfil negociador.

As iniciativas adotadas para organizar a base de apoio ao comércio de serviços, tais como o estabelecimento da SCS e a criação da Câmara de Exportação de Serviços, também têm sido objeto de comentários não muito favoráveis.

Alega-se, por exemplo, que a estrutura recentemente implantada não teria a capacidade de gestão exigida para impulsionar o desenvolvimento desse mercado, e que, na realidade, o seu espectro de ação estaria concentrado no comércio varejista e de atacado, desconsiderandose, consequentemente, todas as demais vertentes dessa atividade econômica e os seus respectivos níveis de desagregação.

\section{Considerações Finais}

Imagina-se que em um processo de formação de juízo que exprima os interesses de um país, afigura-se meritório, e talvez adequado, a adoção de um procedimento tal qual o implementado por nossas autoridades, que compreende em cooptar, de forma sistemática, os setores representativos de nossa sociedade civil, além, é claro, das entidades governamentais intervenientes no comércio de bens e de serviços, qualquer que seja o seu nível de interferência, para que esses atores contribuam com as suas opiniões e pensamentos, de maneira a legitimar e fortalecer o posicionamento nacional.

No entanto, o poder de barganha de um país em vias de desenvolvimento, detentor de uma pequena cota de participação nas trocas econômicas internacionais, tende naturalmente a ser menor do que aquele apresentado pelas nações mais ricas, nas discussões dos grandes temas constantes das agendas multilaterais de negociação, sobretudo em função do seu respectivo nível de desenvolvimento econômico e social.

Para essas nações emergentes, que isoladamente não dispõem de uma grande capacidade de pressão, a estratégia apropriada para suportar essa disputa de pontos de vistas que em princípio se revelam antagônicos e, eventualmente, descompassados, talvez seja a aproximação com um número expressivo de países que possuam objetivos convergentes. É o caso do G-20, bloco integrado por países como África do Sul, Chile, China, Brasil, Índia e México, estabelecido, fundamentalmente, com o objetivo de construir e suportar um entendimento multilateral que preveja a eliminação dos subsídios agrícolas oferecidos pelos EUA e Comunidade Européia aos seus respectivos setores produtivos, combinada com uma maior expansão das condições de acesso aos mercados internacionais.

Ainda que a posição sustentada por um bloco que contemple as mais diversas aspirações, de países que apresentem entre si assimetrias em níveis significativamente altos, a construção de um consenso naturalmente leva em consideração os sentimentos em particular

perfil e o comportamento do comércio Brasil-China, para subsidiar a reação imediata de nossa "Defesa Comercial", ao menor sinal de avanço abusivo dos chineses ao nosso mercado, nesse novo contexto. 
das partes, onde cada um dos atores admite realizar concessões mútuas, o que, na verdade, é algo inerente ao conceito de consenso.

Não obstante à formulação desse entendimento, no âmbito das negociações internacionais, é preciso lembrar que o futuro é cheio de incertezas. Nada assegura que uma decisão adotada num determinado instante, em consonância ou não com a tendência ou atual vertente dos movimentos, ou mesmo por uma orientação política dominante, venha se mostrar vitoriosa em longo prazo, haja vista que aspectos conjunturais relevantes podem alterar o curso dos acontecimentos.

De qualquer forma, ainda que a História venha comprovar que uma certa opção, de fato tenha sido efetuada fora da rota ideal de cruzeiro, cabe à cúpula negociadora corrigir os desvios que porventura sejam detectados, redirecionando o comando das ações para neutralizar os efeitos negativos decorrentes de uma aposta em determinado rumo para as discussões internacionais.

Por outro lado, face à evolução e ao crescimento do comércio de serviços, torna-se evidente, no caso brasileiro, a necessidade de organização do nosso mercado interno, de maneira a nos credenciarmos a postular um lugar de destaque nos negócios da espécie, até porque, num contexto de globalização, o acesso de intervenientes estrangeiros ao País, mais cedo ou mais tarde será maximizado, em função das concessões que forem admitidas, nas rodadas internacionais de negociação.

Considerando essa linha de pensamento, parece-nos impreciso assumir como verdade que a estrutura estatal brasileira recentemente formatada para a gestão do mercado de serviços, venha se preocupar com a aplicação de políticas públicas privilegiando apenas alguns setores, ou sub-setores que, em princípio, se afigurem relevantes, embora a ressonância dos primeiros movimentos externados nesse sentido eventualmente estejam confirmando essa tendência inicial.

É claro que o modelo organizacional ora em prática pode não se revelar de todo adequado para o suporte a contento do comércio de serviços, de maneira a influenciar, em curtíssimo prazo, o alcance dos resultados esperados em níveis satisfatórios.

Cabe ao Estado monitorar a força desse mecanismo, com vistas a calibrá-lo, se for o caso, para que a busca pelo atendimento das metas fixadas não se perca.

Todavia, não acreditamos que esse seja o maior problema que particularmente temos a oportunidade de vivenciar no Brasil. Acima de tudo, é preciso que seja estabelecida uma política para o desenvolvimento do mercado de serviços que seja competente para atuar como coadjuvante da redução da vulnerabilidade externa do País.

Para que isso ocorra, é importante nos preocuparmos com a geração das condições ideais para a alavancagem das exportações de serviços, iniciativa que, na visão da Associação de Comércio Exterior do Brasil - AEB, basicamente reside no combate aos fatores subjetivos, informativos e operacionais, determinantes das dificuldades que interferem negativamente no crescimento de nossa performance no cenário internacional. 
Esses fatores decorrem de uma visão geral equivocada do mercado serviços, que considera essa atividade econômica como sendo única e indivisível, e com isso, deixa de observar as necessidades e aspectos particulares de cada sub-setor, além da não existência de uma base de dados estatísticos fidedignos, em combinação com um nível crítico de burocracia e gravação dos negócios vinculados ao segmento, impedindo a valorização dessa atividade e atração de novos intervenientes.

Para superarmos os desafios gerados em decorrências dos desníveis econômicos e sociais que temos sido obrigados a enfrentar nos últimos anos, como prevê a atual política voltada para a promoção do desenvolvimento industrial, tecnológico, e do comércio exterior, fundamentalmente é preciso viabilizar de forma eficiente o incremento quantitativo e qualitativo dos setores produtivos, inserido nesse contexto o mercado de serviços, porque a verdade é que não há alternativa de crescimento econômico que não pressuponha a inserção competitiva no mercado externo das nossas empresas exportadoras de bens e prestadoras de serviços.

\section{Referência Bibliográfica}

Coutinho, Dirceu M. Globalizantes \& Globalizados. São Paulo: Aduaneiras, 2003.

De Negri, Fernanda. Concorrência Chinesa no Mercado Brasileiro: possíveis impactos da concessão, para a China, do status de economia de mercado. Brasília: IPEA, março: 2005. (Nota Técnica - Boletim de Conjuntura)

Foschet, Mozart. Relações Econômicas Internacionais. São Paulo: Aduaneiras, 2001.

Gonçalves, Reinaldo. O Brasil e o Comércio Internacional: Transformações e Perspectivas. São Paulo: Contexto, 2000.

Governo Federal. Diretrizes de Política Industrial, Tecnológica e de Comércio Exterior. Brasília: Governo Federal, 2003

Guidolin, Benedito. Economia Internacional e Comércio Internacional ao Alcance de Todos. São Paulo: Aduaneiras, 1991.

Instituto de Estudos para o Desenvolvimento Industrial. O Comércio Exterior Brasileiro em 2004. São Paulo: IEDI, 2004.

Júnior, Alberto do Amaral. OMC e o Comércio Internacional. São Paulo: Aduaneiras, 2002.

Lopez, José Manoel Cortiñas \& SILVA, Marilza Gama. Comércio Exterior Competitivo. São Paulo: Aduaneiras, 2004. 
Maia, Jayme de Mariz. Economia Internacional e Comércio Exterior. São Paulo: Atlas, 2001.

Marconini, Mário. Acordos Regionais e o Comércio de Serviços. São Paulo: Aduaneiras, 2003.

Moreira, Benedicto F. A construção de uma Política de Exportação de Serviços. Rio de Janeiro: AEB, 2006.

Pinheiro, Armando C., Markwald, Ricardo e Pereira, Lia V. (orgs). O Desafio das Exportações. Rio de Janeiro: BNDES, 2002.

Thorstensen, Vera. OMC - Organização Mundial do Comércio. São Paulo: Aduaneiras, 2001. 